THURSDAY, FEBRUARY I2, I880

\section{EDISON AND THE ELECTRIC LIGHT}

$M R$. EDISON has once more come forward with an $M$ electric lamp, which we are assured solves the problem of the economic subdivision of the electric light. We have heard this statement so many times with respect to one form or other of lamp devised by this most ingenious and indefatigable inventor, each of which in turn has come to no tangible result, that it becomes harder than ever to trust to the rash announcements flourished so airily by the new spaper press on both sides of the Atlantic.

What is then the nature of the inventions thus heralded before the world? Regarded quietly, and without prejudice, from a scientific standpoint, what is the value of the discoveries which can thus play havoc on the Stock Exchange?

A recent number of the New York Herald contained a long and detailed history of Edison's experiments on electric lighting, from which the following description of the new lamp is taken :-

"With a suitable punch there is cut from a piece of 'Bristol' cardboard a strip of the same in the form of a miniature horseshoe, about two inches in length and oneeighth of an inch in width. A number of these strips are laid flatwise in a wrought iron mould about the size of the hand and separated from each other by tissue paper. The mould is then covered and placed in an oven, where it is gradually raised to a temperature of about six hundred degrees Fahrenheit. This allows the volatile portions of the paper to pass away. The mould is then placed in a furnace and heated almost to a white heat, and then removed and allowed to cool gradually. On opening the mould the charred remains of the little horseshoe cardboard are found. It (sic) must be taken out with the greatest care, else it will fall to pieces. After being removed from the mould it is placed in a little globe and attached to the wires leading to the generating machine. The globe is then connected with an air-pump, and the latter is at once set to work extracting the air. After the air has been extracted the globe is sealed, and the lamp is ready for use. . . The entire cost of constructing them is not more than twenty-five cents."

Since the date of this article a paper has been published in Seribner's Monthly Magazine for February, written by Mr. Upton ("Mr. Edison's mathematician") but attested by Mr. Edison's signature as the "first correct and authoritative account" of the invention, which confirms the Herald article to the minutest details.

We fear Mr. Edison is thirty-five years behind the time in his new invention. The patent-roll of Great Britain for 1845 contains the specification of a lamp invented by King, in which a thin rod of carbon was placed in an exhausted globe; and the inventor specially dwells on the advantage of the Torricellian vacuum for the purpose. A similar lamp was designed by Lodyguine in 1873 . The only difference between these lamps and that now brought forward is that Edison prefers a different, and apparently less durable, kind of prepared carbon to that employed by his predecessors, though, again, in the employment of carbonised paper he has been more than once anticipated.

We need not animadvert on the reckless and amusing VoL. XxI.-No. 537] statements made by newspaper correspondents and interviewers; for these accounts, we believe, Mr. Edison cannot be held responsible. Mr. Edison's first steps in electric lighting, we are told, were to invent a lamp and a generator. The lamp consisted of a piece of platinum to be made incandescent, and so arranged that any excess of heat would cause a small lever to cut off the current. It was an old device described by Draper in 1847 . The generator was, on the otber hand, a startling novelty. Instead of causing, as in all ordinary dynamo-electric machines, a set of coils to revolve about an axis in a magnetic field, Edison proposed to mount the coils upon the prongs of a huge tuning-fork which should be vibrated by a steam-engine. The friction and waste of power inseparable from rotation was to be completely abolished. Unfortunately " the machine was not practical, and it was laid aside." In other words it was a hopeless failure, wrong in design, wrong in principle, useful only in showing how singularly devoid of sound scientific knowledge a clever practical man may be. The next idea was to make the incandescent metallic strip give light by proxy, causing it to communicate its heat, either directly or by the intervention of reflectors, to a piece of lime or zircon. The fusible nature of platinum, however, spoiled his efforts, and he proposed expensive alloys of iridium and osmium, only to find, what all experimenters with incandescent metals had long known, that there is a constant disintegration going on at the surface and a consequent waste. Mr. Edison discovered, what is for every student of the theory of electricity the most simple and obvious conclusion from Joule's law, namely, "that economy in the production of light from incandescence demanded that the incandescent substance should offer a very great resistance to the passage of the electric current." Forthwith the spirals of platinur., iridium, and iridio-osmium were tbrown aside. A carbon filament prepared from charred paper, as described, was adopted. It will be difficult to convince us that the fragile horseshoe paper cinder will resist disintegration better than the carbon used in exhausted tubes by dozens of other experimenters; indeed the invention is avowedly so recent that no lamp can have been tried for a period of time long enough to warrant an assertion of its permanence. The latest telegrams from the States inform us that Edison finds great difficulty in maintaining good vacua, and that further experiments are necessary. It must not be forgotten that even in a globe exhausted to one-millionth of an atmosphere, there yet remain many millions of millions of molecules of air enough to make the disintegration of the incandescent carbon fibre only a question of time.

Meantime Edison had "discovered"-what had been known in Europe for many months-that mercurial airpumps could be constructed to exhaust to one-millionth of an atmosphere; and, what is more to the point, he found a workman formerly in the employ of the late Herr Geissler, of Bonn, to make his pumps and glass bulbs for him. The tuning fork generator had already been abandoned in favour of a new generator, christened the Faradic machine, which embodied no new principle nor indeed any very important improvement in construction, being essentially a modification of the well-known Siemens' machine, having a longitudinally-wound armature rotating between the poles of a powerful electro- 
magnet, which in this new form is vertical and provided with unusually massive cheeks. One detail of construction is, however, singular, though it seems to have escaped the notice of electricians. Beneath the longitudinal strands of covered wire the central core of the armature, which is of wood, is overspun with a few layers of iron wire wound transversely. This layer of iron resembles in a kind of way the iron ring in the armature of the Gramme machine, and though no conducting wires traverse the interior of it, it clearly may serve one of the important functions of the iron ring in the Gramme machine in concentrating the lines of force in the field. In support of the allegation that this machine gives out in electricity 90 per cent. of the energy it receives from the driving engine, Mr. Edison caused certain calculations by Mr. Upton to be published in the Scientific American. We have examined these calculations and find that they are based on the supposition that the electromotive force of the generator is a constant quantity when the speed of revolution is constant, and independent of the resistances of the circuit and of the quantity of current generated. This can only be true if the field magnets are excited by a separate current and generator. Now, in the numerical calculations which have thus been put forth in proof of the above assertion, there is no statement made as to the power necessary to supply this auxiliary current, nor indeed are any statistics whatever given of the actual power (in foot pounds or any other measure) delivered by the driving engine to the generator; only a cut-and-dry calculation to show that if the external resistance be greater than the internal the machine will theoretically work more economically when not generating the maximum current! In the Scribner article it is explicitly stated that a second Faradic machine is used to render active the magnets of the machine which supplies the light, and in two admirable pictures, one of which is a view of the battery of Faradic machines set up in a "central station," the nature of the arrangements is shown.

We need not refer in detail to the enthusiastic inconsistencies in the Times correspondent's accounts. Upon Edison's own data, electricity, instead of costing onefortieth of the price of gas, costs at least seven-eighths as much, or about thirty-five times as dear as the Times correspondent declares. As to the cost of the lamp itself, with its carefully incinerated horseshoe of paper, its glass globe exhausted to one-millionth of an atmosphere, and its platinum-connecting wires, we confess we do not know where the work could be done for anything like the cost of a shilling. "The current can be transmitted on wire as small as No. 36," says the Times reporter, who, probably being unaware that the resistance of a yard of such wire is at least half an ohm, avoids saying what length of such wire may be used. With a generating machine "in a central station, perhaps a half-mile away," the introduction of 400 ohms' resistance would be serious-to the light.

But apart from the mild absurdities of newspaper correspondents, the more we study the detailed accounts of the new inventions the more we regret that $\mathrm{Mr}$. Edison does not devote some time to learn what has been already done in this field. An inventor who ignores what has been done ought not to be mortified to find himself occasionally forestalled by others in some discovery which he prides himself is his own. Possibly this may explain the inability sometimes shown by an inventor to credit the good faith of a rival who has priority. The worst feature of such a course of thought lies in its absolute incompatibility with a truly scientific spirit. Here the scientific man and the inventor part company; since the habits of accurate thinking and the necessary candour of the scientific method preclude the truly scientific man from ignoring, even for the sake of scientific discovery, that which is already a part of scientific truth. We are doing no injustice to Mr. Edison's splendid genius when we say that it is to the character of the inventor, not to that of the scientific thinker, that he aspires.

What shall we say, finally, to the whole system of these reckless newspaper announcements-for which, as we have said, we ought not to hold Mr. Edison responsible-by which the public mind is periodically fluttered?

The remedy to these things is obvious enough. Let scientific men once and for all repudiate these false and unwholesome displays of ignorance. Let public opinion insist that the inventor shall be allowed to pursue his way unhampered by the officious interference of the unprincipled speculators whom his soul abhors, or by the irrepressible unscientific reporter who is only one degree less reprehensible for the part he plays. Whether the latest forms of the invention are doomed to the fate of their predecessors or not, the man who can struggle against failures and discouragements as indomitably as Edison has done deserves to succeed, however erratic his methods. But if he succeeds ultimately, it will be in spite of the vampires of the Stock Exchange and the hangers-on of the New York press, who dog his steps for their own selfish ends.

\section{THE MOTION OF FLUIDS}

A Treatise on the Mathematical Theory of the Motion of Fluids. By Horace Lamb, M.A., formerly Fellow and Assistant Tutor of Trinity College, Cambridge; Professor of Mathematics in the University of Adelaide. (Cambridge University Press, I879.)

NOT the least part of the good that must be attributed to the publication of the first volume of Thomson's and Tait's "Natural Philosophy" is that, as in the cases of Maxwell's "Electricity" and Lord Rayleigh's "Sound," it has led and prepared the way for the complete revision and great advancement of several branches of mathematical physics at the hands of those who have made a special study of these branches. Lamb's "Theory of the Motion of Fluids" must be looked upon as another, and for the most part a worthy, offshoot of this wonderful volume. Although it would be too much to expect that one so young as Mr. Lamb should display the same masterly knowledge of his subject as has been displayed by the authors of the two previously-mentioned works, still the thoroughness with which the very difficult and somewhat extensive literature has been handled, and the appreciation of the mathematical points displayed by the author, together with a rare facility in abbreviating and expressing, render this in most respects about the best possible text-book of which the present state of the subject admits. Having said this, it will be seen that I do not make the following remarks with any view of disparaging the 